\title{
RECIFE, A NOIVA DA REVOLUÇÃO: \\ ENTRE OS CIRCUITOS ESPACIAIS DA INCLUSÃO/EXCLUSÃO

\author{
E A RESISTÊNCIA URBANA CONTEMPORÂNEA
}

\section{RECIFE, THE BRIDE OF THE REVOLUTION:}

BETWEEN THE SPATIAL CIRCUITS OF INCLUSION/EXCLUSION

AND CONTEMPORARY URBAN RESISTANCE

\section{Alexandre Sabino do Nascimento}

Universidade de Pernambuco, Petrolina, PE, Brasil

R E S U M O : Para alcançar o conclamado direito à cidade são necessárias políticas urbanas de estruturação e planejamento verdadeiramente democráticas e que atuem, sobretudo, na regulação do uso e ocupação do solo. Tais políticas só são possiveis por meio de uma práxis urbana fundamentada em instrumentos de democracia direta. Neste artigo, analisamos o caráter protagonista e revolucionário do Recife na história brasileira, ligando-o às contradiçóes sociais e à evolução dessa cidade como uma das mais desiguais do pais. O Recife é, atualmente, palco de uma produção do espaço associada a inovações e a projetos urbanos que produzem circuitos espaciais de inclusäolexclusão, com destaque para o Projeto Novo Recife. Todo esse conjunto de elementos recrudesce o caráter segregativo da cidade e também dá margem para o surgimento de movimentos sociais com estratégias e táticas voltadas para a construção de uma nova prática social, marcada por tentativas de educaçáo para a práxis urbana e por atos de ocupaçáo do espaço público, como pode ser visto, por exemplo, nas atividades culturais e politicas realizadas na regiäo do Cais Estelita. Esse cais, além de ser o local onde se insere o Projeto Novo Recife, é cenário de experiências revolucionárias relacionadas à questão urbana.

P A L A V R A S - C H A V E : cidades rebeldes; circuitos espaciais da inclusãol exclusâo; movimentos sociais; metrópole; reestruturação urbana; Recife; direito à cidade.

$$
\begin{array}{r}
\text { Recife, cruel cidade, } \\
\text { Águia sangrenta, leão. } \\
\text { Ingrata para os da terra, } \\
\text { boa para os que náo são. } \\
\text { Amiga dos que a maltratam, } \\
\text { Inimiga dos que não, } \\
\text { este é o teu retrato feito } \\
\text { com tintas do teu verão } \\
\text { e desmaiadas lembranças } \\
\text { do tempo em que também eras } \\
\text { noiva da revolução. } \\
\text { (Carlos Pena Filho) }
\end{array}
$$




\section{INTRODUÇÃO}

O Recife, como as demais metrópoles periféricas e incompletas brasileiras (MARICATO, 2011), vive uma gama de problemas urbanos, estando inserido em um amplo e caótico quadro de constantes engarrafamentos, moradias irregulares, especulação imobiliária e serviços públicos precários. De modo geral, esse quadro fez com que eclodisse, em junho de 2013, revoltas urbanas em diferentes partes do Brasil, em torno das quais orbitavam problemas típicos de uma questão urbana, com suas referentes consequências socioespaciais. Nesse contexto, observamos que o investimento em políticas públicas urbanas, como a urbanização de favelas, os grandes projetos de desenvolvimento urbano (GPDUs) (MASCARENAS; BIENENSTEIN; SÁNCHEZ, 2011), a requalificação de áreas centrais e/ou os megaprogramas habitacionais (Programa Minha Casa Minha Vida (PMCMV)), representou um avanço, mas, ainda assim, foi insuficiente. $\mathrm{O}$ chamado direito à cidade é mais complexo, dependendo de políticas urbanas de estruturação e planejamento verdadeiramente democráticas, as quais devem atuar, sobretudo, na regulação do uso e da ocupaçáo do solo, a fim de desmanchar o intricado nó górdio da terra e da especulação fundiária e imobiliária a ela correlatas (MARICATO, 2011).

Acrescentemos que os problemas socioespaciais ligados à questão urbana desenvolvem-se no interior de dois outros processos, a saber: (i) ampliação da concorrência intercapitalista entre diferentes fraçôes do capital, com efeitos nos diferentes espaços; e (ii) reconfiguração constante da luta de classes. Quanto ao segundo processo, no estado de Pernambuco, especificamente, em Recife, notamos a configuração histórica de diversos momentos de revoltas e sublevaçóes sociais, bem como de períodos de recrudescimento e ampliação das contradiçôes ligadas ao processo de acumulação de capital e às crises do sistema capitalista, que produzem efeitos em diferentes temporalidades e espacialidades.

Em 2008, Francisco de Oliveira publica o ensaio Noiva da Revolução. O texto segue a ideia de que o Recife é uma cidade noiva da revolução. Mas quais revoluçôes foram protagonizadas nessa cidade? Vale retomar alguns dos eventos elencados por Oliveira (2008) para ratificar que Pernambuco e sua capital foram palco de um passado revolucionário. Em 1817, surgiu um movimento social revolucionário emancipacionista que propunha, em seu programa, com base nos ideais iluministas e na Revolução Francesa, o direito ao voto, a abolição da escravatura e a constituição de uma república (isto é, a separação da província do Brasil). Historicamente, esse é um dos eventos mais radicais de Pernambuco. Por conseguinte, veio a Confederaçáo do Equador, de Frei Caneca, movimento separatista que, com uma fórmula inovadora para a época, idealizava um pacto entre estados autônomos (Pernambuco, Ceará e Alagoas) - inovadora no sentindo de que pressupunha, inclusive, a saída, a qualquer momento, de um de seus estados membros, caso fosse da vontade deles. Por fim, em 1848, houve a Revolução Praieira. Relembremos que 1848 é, também, o ano do fim do ciclo das revoluçôes burguesas na Europa, sucedidas pelas revoluções proletárias de 1871, como a Comuna de Paris (HOBSBAWM, 1977; MARX, 2011).

Neste artigo, dialogamos e, ao mesmo tempo, damos um ar contemporâneo a esse caráter protagonista e revolucionário da cidade do Recife - "a cidade lendária" do poeta Capiba -, com uma análise de manifestaçóes e lutas atuais, como a do movimento Ocupe Estelita, associado ao Projeto Novo Recife. 
Inicialmente, cumpre enfatizar que o Recife, da segunda metade dos anos 1950 até o golpe militar de 1964 - intervalo em que se dá, segundo Oliveira (2008), “o último namoro da cidade com a revolução" -, foi marcado pelas Ligas Camponesas de Francisco Julião, pelo Comando Geral dos Trabalhadores (CGT), pelo governo municipal e pelo breve primeiro governo estadual de Miguel Arraes (1963), pela prefeitura de Pelópidas Silveira, pelas açôes de Celso Furtado, da Superintendência do Desenvolvimento do Nordeste (SUDENE), de Paulo Freire, do Movimento de Cultura Popular, e pela ascensão - e seu melhor momento - do Partido Comunista original (OLIVEIRA, 2008).

Comparando esse passado com as atuais manifestaçôes, surge uma pergunta: será que estaríamos vivendo um novo namoro com a revolução? Se sim, esse namoro seria resultado do recrudescimento, em uma nova escala, das desigualdades sociais no espaço da cidade do Recife?

Lefebvre (1999) afirma que a transformação plena da sociedade urbana revolucionária se daria com práticas espaciais dentro de um espaço conflitivo e dialético. Ademais, ele demonstra que, por meio de uma práxis urbana, a problemática urbana seria não apenas um exercício do pensamento, mas também uma prática social. Em Recife, isso pode ser visto, por exemplo, nas tentativas de educação para a práxis urbana e nos atos de ocupaçấo do espaço público, via atividades políticas e culturais na área do Cais Estelita e no restante da área central da cidade. Essas açóes produzem uma racionalidade própria e uma abertura, nos termos de Lefebvre (1999), do campo das possibilidades e alternativas para o uso dos espaços públicos da cidade.

A luta de classes no ambiente construído é o pano de fundo para muitas das revoltas populares nas cidades e para a constante reproduçấo de seu espaço social (LEFEBVRE, 1999; 2006) ${ }^{1}$. Entendemos que os espaços do capitalismo contemporâneo - nos quais acontecem as inovaçôes espaciais (CORREAA, 2010), representadas aqui pelos grandes negócios de reestruturação urbana (shoppings, condomínios fechados, vias expressas, entre outros) - tendem a eclipsar todos os outros espaços da cidade (isto é, os espaços da cultura, do patrimônio arquitetônico cultural, do cotidiano, do encontro) por meio da produção de um espaço geográfica e socialmente desigual, uma produção marcada por processos de fragmentação, homogeneização e hierarquização do espaço (LEFEBVRE, 1999; 2006). São formados, desse modo, verdadeiros circuitos espaciais urbanos inclusivos/excludentes, logo altamente contraditórios. Esses circuitos, quando analisados adequadamente, revelam a natureza opressiva escondida por trás do "véu espacial", ou seja, da paisagem aparente, das imagens e ícones da modernidade e do progresso.

Encobertos por essa paisagem aparentemente moderna e sem contradiçóes, encontram-se os conflitos entre as classes sociais na cidade e os conflitos pelo funcionamento da cidade, que se intensificam à medida que se aprofundam a divisão social do trabalho e a oposição de interesses - não só entre capital e trabalho, mas também entre segmentos do capital e do trabalho.

Lefebvre (1999; 2006) ajuda-nos a compreender a lógica conflitiva e dialetizada da produção de espaços na cidade capitalista através da transformação dos valores de uso em valores de troca, dos espaços públicos em espaços privados, como o que acontece no Projeto Novo Recife. Considerando isso, podemos questionar: o que se está processando nos espaços que representam o patrimônio arquitetônico cultural do Recife é somente uma supervalorização do valor de troca, em detrimento dos valores de uso para seus cidadãos, ou, ao contrário, há realmente uma conscientização dos
10 filosofo francês Henri Lefebvre, de um modo geral, dá atenção à produção do espaço e à sua consequente reprodução na sociedade contemporânea. Ele examina, entre outras questões, as mudanças no espaço operadas pelo mundo da mercadoria. Efeitos como decomposição das cidades e processos como "implosão-explosão", "homogeneização", "fragmentação" e "hierarquização" do espaço foram amplamente desenvolvidos por ele para explicar as mudanças na cidade. Tais temas podem ser vistos nas obras De lo rural a lo urbano (1969), A Revolução Urbana (1999) e A Produção do Espaço (2006). Esta última é considerada sua principal obra no tocante à (re) produção do espaço. 
2 Relatórios de Avaliação do Governo da Secretaria de Planejamento e Gestão (SEPLAG-PE). Disponível em: <http://www.seplag.pe.gov. br/web/r.a/ra-relatorios-de -avaliacao\#\&panel1-1\&panel2-1 1 . Acesso em: 30 ago. 2015. cidadãos quanto à história local? E ainda: as lutas em torno desses espaços da cidade envolvem movimentos citadinos plurais e interclassistas (CASTELLS, 1980), novos movimentos urbanos ligados ao ciberespaço e às redes de internet, ou apenas projetos de uso e valorização de espaços ligados a determinadas fraçôes da classe média da metrópole do Recife?

Para responder a tais questóes, começamos o texto com uma análise conjuntural da metrópole do Recife, fazendo um sobrevoo sobre sua atual realidade socioeconômica e histórica. Em seguida, examinamos a conformação do que chamamos de circuitos espaciais de inclusão/exclusão urbana, ligados a processos de homogeneização, fragmentação, hierarquização e à produção do espaço urbano via "inovaçôes espaciais". Nessa parte, retomamos conceitos de autores como Milton Santos, David Harvey, Roberto L. Corrêa, Henri Lefebvre, entre outros. Após isso, discorremos sobre a emergência e a importância dos movimentos sociais urbanos, especialmente no Recife, destacando suas bandeiras e formas de luta contemporâneas. Por fim, apresentamos as consideraçôes finais e algumas de nossas inquietaçôes acerca do tema das cidades e de seus movimentos insurgentes.

\section{PANORAMA DA DINÂMICA SOCIAL E ECONÔMICA DA METRÓPOLE DO RECIFE E SUAS CONTRADIÇÕES}

A capital de Pernambuco passou a disputar, nos últimos anos, um lugar no hall das metrópoles periféricas emergentes, centrando-se na produção e no consumo desigual de seu espaço urbano. Nela, houve um crescimento do mercado de bens duráveis e do consumo. Esse aumento trouxe novos atrativos em investimentos com vistas a atender aos mercados crescentes, assim como demandou infraestruturas de toda sorte e bens de consumo duráveis, como habitação (HARVEY, 2013).

Segundo dados do Plano Plurianual de Pernambuco 2012-2015, o principal vetor das mudanças foi, sem dúvida, o bloco de investimentos públicos e privados que o estado atraiu nos últimos anos. Em 2010, o Produto Interno Bruto (PIB) pernambucano cresceu 9,3\%, situando-se acima do percentual nacional, que também apresentou o maior nível de crescimento da década, isto é, 7,5\% $\%^{2}$. O estado também passou por uma mudança na estrutura industrial no médio prazo, fruto da onda de recentes investimentos, notadamente na região do Complexo Industrial Portuário de Suape (CIPS) e no litoral norte.

Tudo isso conduziu à atração de mão de obra especializada e ao aumento dos rendimentos. Outra consequência foi a abertura de nichos de produçâo imobiliária para os potenciais novos moradores/consumidores da metrópole, favorecendo a especulação imobiliária. Atualmente, o mercado imobiliário do Recife sofreu certa reduçáo no número de espaços urbanizados e bem localizados. Daí termos uma investida dos promotores imobiliários na área central da cidade, onde se localiza o cais José Estelita, representante de um espaço urbanizado com caraterísticas históricas e simbólicas muito fortes. Essa região da cidade, diante da saturação de projetos e empreendimentos imobiliários voltados para classes média e média alta em áreas nobres, como o litoral sul e a regiáo norte, é um espaço com características que podem auferir rendas de monopólio para seus controladores (HARVEY, 2005). 
Outro fator importante para nossa análise é a evolução, ou não, dos rendimentos dos trabalhadores. Na Região Metropolitana do Recife (RMR), observa-se a predominância de baixos salários. De acordo com a Pesquisa Nacional por Amostra de Domicílios (PNAD) de 2012, nela, 39,2\% dos trabalhadores recebem até 1 salário mínimo; 46,7\% recebem de 1 a 3 salários. Apenas 14\% ganham acima de 3 salários mínimos (SERVIÇO BRASILEIRO DE APOIO ÀS MICRO E PEQUENAS EMPRESAS, 2014).

Em contrapartida, em 2012, o preço do metro quadrado no Recife subiu $17,8 \%$, maior variação do país entre as sete capitais pesquisadas pelo Índice FipeZap de Preços de Imóveis Anunciados, com base em cálculos da Fundação Instituto de Pesquisas Econômicas (FIPE). O preço médio do metro quadrado chegou a R \$ 5.536 em dezembro, segundo levantamento divulgado em janeiro de 2013 (PREÇO, 2013). Conforme Freitas (2012), os preços dos imóveis no Recife subiram 36,6\% entre 2011 e 2012 , enquanto a taxa brasileira foi de $24,8 \%$ no mesmo período. Houve, como mostram os dados, um crescimento da exclusão socioespacial nessa cidade, pois a renda média do trabalhador recifense manteve-se muito aquém da escalada de preços dos imóveis. Podemos dizer, assim, que o aumento do custo das moradias na cidade foi afetado, numa espécie de efeito dominó, pela especulação imobiliária.

Nesse cenário, foram produzidos espaços nas adjacências da bacia do rio Pina. Exemplos disso são os grandes projetos como a Via Mangue, o Shopping RioMar, o Porto Novo e o Projeto Novo Recife, os quais se configuram como grandes negócios para um grupo seleto de empreendedores e tendem a proporcionar altos lucros para o mercado imobiliário. É preciso pontuar que tais empreendimentos estáo ligados à busca por melhor qualidade de vida dos setores da classe média alta do Recife e conformam um verdadeiro circuito espacial de inclusão/exclusão socioespacial aspecto analisado no próximo tópico.

Entre os fatores apresentados por Harvey (2011) como ingredientes de sucesso para a gestão urbana do Estado na captação e no uso de investimentos, está a criação de condiçóes favoráveis à qualidade de vida. Nos últimos anos, o Recife vem se posicionando como uma das capitais que mais crescem economicamente no país. Apesar de todo esse crescimento, a cidade ainda é uma das mais desiguais em termos de concentraçáo de renda, conforme indicadores de qualidade de vida divulgados pelo movimento Observatório do Recife (ODR) e números do Índice de Bem-Estar Urbano (IBEU).

O Recife foi líder em desigualdade social no Brasil durante os últimos 20 anos, aproximadamente. A cidade é apontada como a capital nacional das disparidades entre o total populacional e a concentração de renda. A capital pernambucana tinha, em 2010, a terceira pior linha de miséria do Brasil - famílias cuja renda per capita mensal é menor ou igual a 1/4 do salário mínimo -, perdendo apenas para Maceió/AL, 14,35\%, e Macapá/AP, 15\%. Em dezembro de 2010, segundo dados compilados pela Relação Anual de Informaçóes Sociais/ Cadastro Geral de Empregados e Desempregados/Ministério do Trabalho e Emprego (RAIS/CAGED/ TEM), 56,07\% dos trabalhadores registrados ganhavam, no máximo, dois salários mínimos e absorviam $21,78 \%$ de toda a massa salarial. No mesmo mês, apenas $3,05 \%$ dos trabalhadores registrados ganhavam 15 ou mais salários mínimos, concentrando 22,96\% da massa salarial (OBSERVATÓRIO DO RECIFE, 2015). Somemos, a isso, o fato de que, de acordo com o censo de 2010, 1/4 da populaçáo 
recifense residia em favelas.

O geógrafo Jan Bitoun, analisando os indicadores de desigualdade do Recife, afirma que o coeficiente de Gini - índice que aponta quão distinta é a distribuição de renda entre os cidadãos - está longe de ser bom: de 0,6739, em 1991, o índice passou para 0,6894, em 2011, estando bem acima de metrópoles como São Paulo. Ele também assinala que, diferentemente de cidades como Campinas/SP, cujos Índice de Desenvolvimento Humano Municipal (IDH-M) e IBEU estão, juntos, na liderança nacional, Recife mostra uma realidade distinta entre o potencial do que poderia ser e o que, de fato, oferece aos moradores.

Para Bitoun, entre os principais motivos para a ocorrência desse quadro, estão a organizaçáo do espaço e a disparidade social da cidade, que, em nossa análise, vem se agravando com a atual produção de GPDUs. Em relação à produção de um espaço cada vez mais desigual e sua relação com a renda dos moradores, o autor pontua:

O problema é que a lógica dos serviços e equipamentos públicos está diretamente ligada à renda alta concentrada com poucas pessoas. A solução privada substitui a pressão sobre o poder público por soluções urbanísticas no município. A camada mais alta da sociedade é justamente a que pode fazer escolhas, mas ela não investe na ideia do "público" e o estilo de vida passa a ser "modelo" para todo mundo. O resultado é que a distância entre desenvolvimento e bem-estar faz parte do fato de a populaçáo ficar alheia à mediocridade do espaço público (BITOUN apud MUITAS, 2013, n. p).

Sublinhemos, ainda, que quase $97 \%$ dos aglomerados subnormais de Pernambuco encontram-se na Região Metropolitana do Recife (RECIFE, 2011). Essa concentração recebeu destaque no relatório da pesquisa Aglomerados Subnormais Informaçôes Territoriais do Instituto Brasileiro de Geografia e Estatística (IBGE). A esses dados, alinham-se os do déficit habitacional. Segundo relatórios da Fundação João Pinheiro (2013), a RMR tem o déficit de 143.235 mil domicílios - 12,9 \% do estoque de domicílios particulares permanentes. Desse número, 62.687 domicílios correspondem à cidade do Recife.

A carência de infraestrutura urbana é o critério de inadequação que mais afeta os domicílios das regióes metropolitanas (RMs) brasileiras. Considerando as regiôes metropolitanas de capitais, o maior número de domicílios afetados por pelo menos um componente da infraestrutura urbana é observado nas RM do Rio de Janeiro

30 Occupy Wall Street representa um movimento de protesto contra a desigualdade econômica e social, a ganância, a corrupção e a indevida influência das empresas, sobretudo do setor financeiro, no governo dos Estados Unidos. Movimentos desse tipo vão contra o modelo de política baseado em estruturas verticais e centralizadas, típicas das repúblicas representativas. Eles propõem formas horizontais de decisão, sem personificação de lideranças nem comando de partidos e comitês centrais (ROLNIK, 2013). (717 mil domicílios), de São Paulo (522 mil), Recife (490 mil) e Fortaleza (355 mil). Vemos que a RMR é a terceira metrópole em carência de infraestrutura urbana, apresentando um percentual que corresponde a 45,2\% de domicílios particulares permanentes, o que vai de encontro com os números de sucesso apresentados pelos governos locais.

Apesar de todos esses números problemáticos, atualmente, na sociedade recifense, a discussão urbana mais divulgada gira em torno do Projeto Novo Recife. Esse projeto - representante do modelo de produção do espaço abstrato do capitalismo - está imerso em uma batalha que envolve a produção e a apropriação do espaço, consubstanciada na luta de empreendedores urbanos (Construtora Moura Dubeux e Queiroz Galvăo, principalmente), em aliança com o Estado, contra grupos de ativistas e movimentos sociais, como o Ocupe Estelita, surgido em 2012. Inspirado no Occupy Wall Street ${ }^{3}$, tal movimento convocou todos os descontentes com a forma 
de articulação do consórcio Novo Recife Empreendimentos a tomar as calçadas (e o interior, em algumas ocasióes) dos armazéns do cais José Estelita com o objetivo de impedir a sua destruição.

\section{OS CIRCUITOS ESPACIAIS DA INCLUSÃO/ EXCLUSÃO E A PRODUÇÃo DA METRÓPOLE CONTEMPORÂNEA}

Atualmente, é impossível pensar o capital e suas metamorfoses sem conectálo à maneira pela qual o espaço é produzido, apropriado e dominado como uma mercadoria. Nesse sentido, as transformaçôes não se dão apenas na esfera da produção, mas também, e principalmente, no âmbito do consumo e da reprodução das relaçóes de produçáo (LEFEBVRE, 1999; 2006; 2008). A esse respeito, Lefebvre salienta que, como disse Marx,

[u]m modo de produçáo não desaparece antes de ter liberado as forças produtivas e realizado todas as virtualidades que ele contém [...]. Afirmação que se pode tratar tanto como uma evidência, quanto como um surpreendente paradoxo. Um salto adiante das forças produtivas - realizado sem que as relaçóes capitalistas de produçáo tenham desaparecido substitui, ou melhor, sobrepóe à produção de coisas no espaço a produção do espaço. Esta acompanha, ao menos em alguns casos observáveis e analisáveis, a pressão do mercado mundial e a reprodução das relaçóes de produçáo capitalistas. A burguesia, despoticamente esclarecida, e o capitalismo dominaram parcialmente o mercado das mercadorias, servindo-se do espaço abstrato como instrumento (LEFEBVRE, 2006, p. 98-99).

Podemos observar, inclusive em Recife, a produção de circuitos espaciais da inclusão/exclusão, os quais são produtores de uma vida cotidiana ligada à reprodução das relaçôes capitalistas de produção (LEFEBVRE, 1991; 2006), por meio da construção, nas metrópoles, de formas espaciais representativas de novas espacialidades e temporalidades. Tais formas articulam, conectam, as partes fragmentadas da cidade, verdadeiras ilhas modernas e de prosperidade, através de obras viárias - as chamadas obras de mobilidade urbana, como as vias expressas (Via Mangue), as pontes e os viadutos (Ponte do Paiva). Ademais, visualizamos a profusão de novos lançamentos, havendo, em abundância, a produçáo de locais como shoppings (RioMar), condomínios e loteamentos fechados (Reserva do Paiva, Alphaville, Cidade da Copa, entre outros), que viabilizam o caráter transitório da sociedade, vinculado à alta mobilidade e à circulação do capital.

Para Reynaldo et al. (2013, p. 7), “[o] que se assiste no caso da RMR é um importante processo de fragmentação espacial, com um baixíssimo nível de integração entre as urbanizações propostas e os núcleos urbanos existentes, tanto do Recife como dos municípios onde se localizam”. Já Maricato (2013) aponta que as cidades contemporâneas atuam no processo de acumulação do capitalismo globalizado a partir dos meganegócios, nos quais a produção do espaço urbano, as obras de infraestrutura e as edificaçóes têm um papel essencial. Considerando isso, é fato que a desregulamentação, a flexibilização e a privatização foram práticas que 
4 Lefebvre, em A Produção do Espaço, fala dessa obsolescência e sua ligação com a produção de novos espaços: "[as] dificuldades provenientes da demasiado lenta obsolescência dos produtos, o que tende a acarretar um abrandamento da rotação do capital, [são combatidas] por procedimentos bem diversos. A mobilização do espaço se torna frenética, e compele até a autodestruição dos espaços, antigos e novos. 0 investimento e a especulação não podem parar, [nem] mesmo abrandar: círculo, ciclo infernal" (LEFEBVRE, 2006, p. 456).

5 Essa definição fundamenta-se na releitura e imbricação de conceitos/reflexões de alguns autores, quais sejam: 1. Santos (1978; 2005) - "circuitos da economia urbana" nas cidades de países subdesenvolvidos; 2 . Corrêa (2010) - "inovações espaciais" como formas espaciais típicas da urbanização contemporânea e seus efeitos no espaço urbano; 3. Lefebvre (1999; 2006; 2008) - espaço como sendo simultaneamente fragmentado, homogeneizado e hierarquizado, algo que nasce a partir do modo de produção hegemônico e de suas contradições. acompanharam a reestruturação das cidades, com o intuito de abrir espaço para capitais imobiliários, de infraestrutura e serviços.

Cumpre assinalar, ainda, que, nesse jogo, é estabelecida uma interpenetração entre o público e o privado, percebida na presença reguladora do Estado, nas isenções fiscais, na usura do patrimônio público (doação e leilóes de terrenos estatais), no marketing e na apropriação privada de espaços das cidades (LEAL, 2006). Esse quadro é configurado no interior do atual processo de reproduçáo ampliada do capital, no qual grandes empresas requerem, cada vez mais, grandes negócios (megaprojetos, megaeventos), e estes só se tornam viáveis e factíveis com o auxílio, cobertura e parceria do Estado.

É desse modo que se apresenta o grande negócio da urbanização do Recife, chamado de Novo Recife. Esse grande negócio tem sido objeto de polêmica em função de seu potencial de impacto para o desenvolvimento urbano da cidade, do nível de relaçóes entre Estado e capitais envolvidos em sua produção, via arranjos político-institucionais, e do fato de estar ligado à promoção do desenvolvimento urbano através da produção de projetos urbanísticos espetaculares.

Podemos dizer que o Projeto Novo Recife se aproxima do que Harvey (2011) denomina de "destruição criadora": a necessidade premente de o sistema produzir, por meio da absorção dos excedentes da transformação urbana, novos espaços para fugir das crises de superacumulação. $O$ autor também chama a atenção para a transformaçấo da qualidade de vida e do próprio direito à cidade em mercadoria. Nas palavras dele:

A qualidade de vida urbana tornou-se uma mercadoria para aqueles com dinheiro, assim como para a própria cidade, num mundo onde o turismo, o consumismo, o marketing de nicho, as indústrias culturais e de conhecimento, e também a perpétua dependência em relação à economia política do espetáculo tornaram-se os principais aspectos da economia política do desenvolvimento urbano (HARVEY, 2011, p. 143).

Entendemos a difusão em Recife das chamadas “inovaçôes espaciais” na mesma linha argumentativa de Harvey. Para Corrêa (2010), essas inovaçôes constituem tanto objetos fixos criados pelo homem quanto deslocamentos em geral, fluxos, que são novos ou considerados novos em um dado contexto espacial. Ele também as associa às estratégias de "destruição criadora" (HARVEY, 2011) e de "obsolescência programada” (LEFEBVRE, 1991; 2006), afirmando que as inovaçôes são correntes e efetivadas, cada vez mais, em menores intervalos de tempo.

O produto da inovação, o novo, como demonstra Corrêa (2010, p. 150), é considerado "sinônimo de progresso e bem-estar, tornando-se, graças à massiva publicidade, o mais importante e genérico objeto de consumo. Por seu intermédio, a acumulação de capital estabelece uma de suas bases de continuidade”. Isso é o que está implícito na proposta do Projeto Novo Recife, sobretudo na referência à modernização de uma área caracterizada pelo atraso e por um passado decadente, a qual precisa sofrer uma reestruturação para ocupar um novo papel na divisão social e territorial do trabalho como uma metrópole aberta às influências exógenas, aos novos signos contemporâneos e aos "vitoriosos" modelos de gestão urbana.

Nesse contexto, conforma-se o que intitulamos de circuitos espaciais da inclusão/exclusão urbana em Recife ${ }^{5}$. Tais circuitos são representativos do poder dos agentes hegemônicos na produção do espaço da metrópole, que efetivam mudanças 
qualitativas e quantitativas na dinâmica das cidades e em suas relaçóes sociais. $\mathrm{Na}$ Figura 1, podem ser visualizados esses circuitos próximos à bacia do rio Pina e na regiāo do Cais Estelita, área com localização privilegiada, inserida no centro antigo da cidade, nas margens da área portuária, fazendo parte da frente d'água (waterfront) ou frente marítima do Recife, juntamente do Cais de Santa Rita. Este último é outro espaço portuário que está sendo alvo de um projeto de requalificação designado como Projeto Porto Novo ${ }^{6}$, sob liderança do Governo do Estado de Pernambuco.

Figura 1: Frente marítima do Recife e Grandes Projetos de Desenvolvimento Urbano

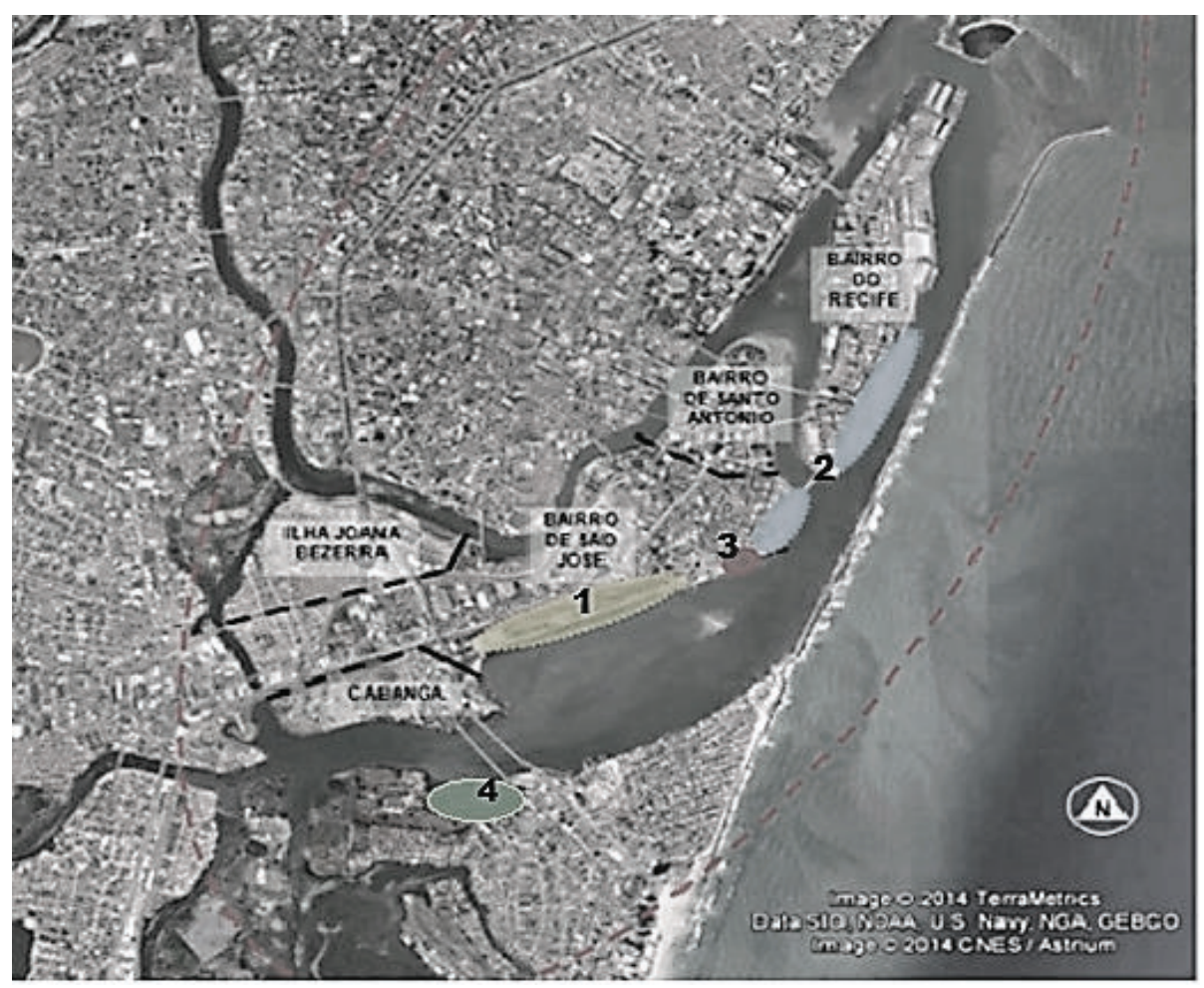

Fonte: Adaptado de Mendonça (2015).

1. Projeto Novo Recife

2. Projeto Porto Novo

3. Torres Gêmeas

4. Shopping RioMar e Via Mangue

Excluída desses circuitos espaciais e enclaves de modernidade, vive e trabalha uma massa de pessoas com baixas expectativas de inserção formal no exigente mercado de trabalho. Esses indivíduos não são contemplados com políticas de mobilidade social ascendente, e, por isso, reproduzem-se em espaços de periferização e exclusão. Uma vez que inexistem como consumidores desses espaços e de alguns serviços da cidade, não são tratados como cidadãos. Eles fazem parte de um mundo cindido pelos padróes sociais absorvidos pela classe dos incluídos, não sendo tolerados em função de sua pobreza e miséria. Nesse grupo, destacam-se os moradores e os trabalhadores que possuem residências e trabalhos localizados nas proximidades dessas áreas e que se ligam a um circuito informal da economia urbana (SANTOS, 1978; 2005; 2008). Adicionemos que tais moradores/trabalhadores não são lembrados e não fazem parte
60 Projeto Porto Novo visa a revitalizar o berço histórico da cidade e a transformar antigos armazéns do Porto do Recife, inoperantes desde 1992, em espaços turísticos e de lazer, tendo os seguintes equipamentos: Terminal Marítimo de Passageiros; cais do Sertão Memorial Luiz Gonzaga; Centro de Artesanato e obras de urbanização do cais. Alguns desses equipamentos ainda se encontram em construção. 
das discussôes e dos debates sobre a área em que vivem, nem dos planos dos agentes hegemônicos produtores do espaço urbano.

Santos (1978), em sua análise da urbanização do Terceiro Mundo, considera tanto a dimensão histórica como a especificidade dos espaços periféricos examinados. Estes, como ele mostra, caracterizavam-se, entre outros fatores, por possuir grandes limitaçóes na capacidade empregatícia de setores intensivos em capital (circuito superior) e por apresentar um alto índice de proliferação da pobreza, bem como uma gama de atividades urbanas de baixa produtividade (circuito inferior), as quais acolhiam uma parcela elevada da força de trabalho - algo muito próximo da realidade de metrópoles periféricas como o Recife. Sobre a origem desses circuitos, o autor afirma:

A presença de uma massa populacional com salários muito baixos, dependendo de trabalho ocasional para viver, ao lado de uma minoria com altos salários, cria na sociedade urbana uma distinção entre os que têm permanente acesso aos bens e serviços oferecidos e os que, mesmo apresentando necessidades similares, não podem satisfazê-las. Isto cria ao mesmo tempo diferenças qualitativas e quantitativas de consumo. Essas diferenças são, ambas, causa e efeito da existência, isto é, da criação ou manutenção, nestas cidades, de dois sistemas de fluxo que afetam a fabricação, a distribuição e o consumo de bens e serviços (SANTOS, 2005, p. 95).

Para Santos (2005), ambos os circuitos são resultados, diretos e indiretos, da modernização - produtos de inovaçôes, portanto. Corrêa (2010) destaca, dentro de um vasto quadro, os seguintes exemplos de inovaçóes espaciais que configuram tais circuitos: "cidadelas" (bairros ou "cidades" planejadas), shoppings centers e vias expressas, sendo estes representativos da organização espacial de setores de amenidades. Para o caso do Recife, podemos adicionar ao quadro os edifícios (torres) de serviços especializados ou empresariais encontrados, hoje, em nossas metrópoles, cada dia mais ligadas a uma economia de serviços típica do circuito superior - aqui se insere, por exemplo, o polêmico Projeto Novo Recife.

Nas novas "cidadelas" ou condomínios de luxo, vive uma classe média alta,

7 Os edifícios Pier Mauricio de Nassau e Pier Duarte Coelho estão localizados no cais de Santa Rita. O terreno pertencia à Mesbla Veículos. A empresa encerrou suas operações com diversas dívidas trabalhistas e acabou perdendo o terreno em disputa jurídica. Posteriormente, esse terreno foi leiloado de forma questionável. Duas empresas tinham interesse em adquirir o local: as construtoras Moura Dubeux e Queiroz Galvão - atualmente, líderes do Projeto Novo Recife. O leilão deveria ocorrer no dia 24 de março de 2003, às 12 horas 30 minutos. Porém, sem notificação oficial, o horário foi modificado para as 9 horas da manhã, aparecendo apenas a Moura Dubex como interessada. constituída por descendentes de famílias de alto status que residiam nos bairros nobres tradicionais ou por uma classe média emergente, procedente de bairros de menor status. Essas áreas podem ser ocupadas, ainda, como vem ocorrendo em Recife, por uma mão de obra vinda de fora para trabalhar em cargos especializados ou de chefia nos vários projetos e nas empresas recentemente instaladas na cidade. As "cidadelas" ou edifícios de serviços especializados ou empresariais - como as Torres Gêmeas ${ }^{7}$ e o Novo Recife - oferecem segurança, variados tipos de lazer, lojas de conveniência, shoppings, restaurantes, marinas, capelas ecumênicas, escolas, entre outros serviços.

Entre os circuitos espaciais criados, recentemente, no Recife, temos, como primeiro exemplo, o Shopping RioMar, que gerou muita polêmica na cidade desde o momento em que foi publicada sua proposta de instalação. As controvérsias em torno do projeto se deram pelo fato de o shopping ocupar uma grande área de mangue, utilizando o frequente discurso (acionado por construtoras e promotores imobiliários) da sustentabilidade e dos edifícios inteligentes e ecológicos para relativizar a ocupação. Uma outra crítica relacionava-se ao provável aumento de congestionamentos em uma localidade que já era conturbada, uma vez que se constituía como entrada principal para a zona sul da cidade e para bairros como o de Boa Viagem. 
Um segundo exemplo está ligado à aliança do Estado com o capital incorporador, representado, entre outros, pelos grandes projetos urbanos realizados pelo grupo JCPM, pertencente a João Carlos Paes Mendonça, antigo dono da terceira maior rede de supermercados do país, Hiperbompreço, que fez fortuna em Pernambuco. Hoje esse empresário atua no ramo imobiliário e de shoppings, principalmente no Nordeste, sendo sócio de três dos principais shoppings da cidade do Recife.

A respeito das obras de mobilidade, podemos citar o caso da via expressa batizada de Via Mangue, localizada em uma área consolidada e de revalorização na porção oeste do bairro do Pina. Essa obra viária pode vir a acarretar uma grande concentração de projetos imobiliários de moradia para as classes média e alta, dado que está inserida em uma das áreas que mais se valoriza na cidade, possuindo as maiores altas de preço por metro quadrado ${ }^{8}$. $\mathrm{O}$ objetivo desse projeto, segundo proposta do governo, é desafogar o trânsito na zona sul do Recife por meio de uma via de $5,1 \mathrm{~km}$ de extensão às margens do manguezal do rio Pina.

A Via Mangue recebeu críticas por ter sido construída sobre ambiente de mangue (Parque dos Manguezais). Como justificativa, foi dito que ela serviria de cinturão protetor para o manguezal e que provocaria a valorização do transporte público. No entanto, essas duas justificativas não passaram de um contrassenso: a via, atualmente, é exclusiva para automóveis particulares, além de causar inúmeros danos ambientais para o manguezal.

Tal projeto serve de exemplo para o entrelaçamento de uma obra pública, no valor aproximado de $\mathrm{R} \$ 24$ milhóes, com interesses do capital imobiliário. Ela liga, em suas extremidades, o Shopping RioMar ao condomínio-resort Le Parc, pertencente aos grupos JCPM e Cyrela Andrade Mendonça. Também é notória a proximidade da Via Mangue ao JCPM Trade Center, localizado no Pina e considerado o empresarial mais luxuoso do Recife, e ao Projeto Novo Recife. Tudo isso, ressaltemos, foi feito sob o discurso da sustentabilidade e do ecologicamente correto. Como diziam, o Le Parc estaria “integrado" ao Parque dos Manguezais, o RioMar teria $40 \mathrm{mil} \mathrm{m}^{2}$ de área verde e a Via Mangue serviria de cinturão protetor ao manguezal.

Acerca dos antecedentes do Projeto Novo Recife, assinalamos que, desde 2003, as prefeituras do Recife e de Olinda já vinham conversando sobre o Complexo Turístico Cultural Recife-Olinda, que, entre outras intervençôes, envolveria um projeto na frente marítima que articula e, ao mesmo tempo, divide as duas cidades. O governo do estado, por sua vez, a partir de uma das diretrizes de planejamento metropolitano formulada em 2002, contratou, via Porto Digital, a Expo-Lisboa empresa pública portuguesa que desenvolveu e gere o projeto de expansão de Lisboa para uma antiga área porto-ferroviária - para produzir um projeto para a área que o complexo ocuparia, uma área muito maior do que a do cais José Estelita, já que atravessava toda a frente marítima entre Recife e Olinda (espaço que concentrava muitos terrenos públicos subutilizados). Sobre esse aspecto, a urbanista Raquel Rolnik, que participou do processo, afirmou em um texto de seu $b \log ^{9}$ :

Como havia terrenos da Uniáo nas áreas que estavam sendo pensadas para o desenvolvimento do projeto, o governo federal foi chamado para disponibilizar suas áreas. Era 2005 e, nesta ocasião, eu era secretária de programas urbanos do Ministério das Cidades, e nós - ao invés de simplesmente ceder ou não as áreas - atuamos na articulação de outros órgãos do governo federal, como a Secretaria do Patrimônio da União e o Iphan, para todos
8 Uma reportagem publicada em maio de 2012 já apontava a escalada de preço dos imóveis no bairro do Pina e suas possíveis causas: "Chama a atenção o preço do metro quadrado no bairro do Pina, que já é o segundo mais valorizado da cidade, ficando em média a $\mathrm{R} \$ 5.359,65$, pouco atrás de Boa Viagem, com $\mathrm{R} \$ 5.492,08$. Dois são os fatores principais para este fenômeno: a requalificação do bairro, com empresariais e a construção do Shopping Rio Mar e a proximidade com o Centro da Cidade. Observando os motivos pelos quais o consumidor escolhe um produto, pode-se inferir que o fatores mobilidade e vizinhança estariam valorizando a região" (LUCENA, 2012, n.p.).

\footnotetext{
9 Texto intitulado "Grupos se mobilizam no Recife contra o projeto imobiliário no cais José Estelita", de 2012.
} 
juntos formularmos um projeto. Foi então criado um Grupo de Trabalho, envolvendo os dois municípios, o Estado de Pernambuco e a União, e aí começamos a discutir o que ficou conhecido como Projeto Urbanístico Recife/Olinda (ROLNIK, 2012, n. p.).

A base do projeto era a disponibilização de espaço público e transporte público de qualidade para interligar as duas cidades. Estavam previstos, por exemplo, 1/3 de habitação popular nas novas áreas a serem construídas, assim como recursos para a urbanização de todas as favelas contidas nesse perímetro. Uma proposta inicial - não totalmente desenvolvida e ainda não sacramentada pelos envolvidos - foi lançada para debate público. Em 2007, no entanto, após as eleiçôes, o governo de Pernambuco mudou, e a nova gestão simplesmente náo deu continuidade ao projeto. Dois anos depois, o mesmo fato aconteceu no Recife. Rolnik (2012, n. p.) faz uma avaliação para esse desfecho do projeto:

Hoje, na minha avaliação, dois fatores terminaram por detonar a possibilidade de implementação do projeto: o governo do Estado, por um lado, resolveu se desfazer dos seus terrenos no perímetro do projeto, privatizando uma área onde hoje está sendo construído um mega shopping center, e o governo federal, por outro lado, decidiu leiloar o terreno da União no cais José Estelita, que foi arrematado pelas três empresas que hoje pretendem implementar na área o Projeto Novo Recife, que nada tem a ver com o plano que estava em desenvolvimento e sua estratégia mais global e intersetorial de implementação.

Atualmente, presenciam-se lutas ou apelos na cidade em prol de um Patrimônio Artístico Cultural e Arquitetônico, pois o Projeto Novo Recife está projetado para ser efetivado no cais José Estelita, que possui, na área do entorno, monumentos tombados pelo IPHAN. Por lei, essas áreas possuem restrições de construção, justamente para possibilitar a visualização dos monumentos tombados, isto porque o usufruto e a contemplação da paisagem histórica e cultural do Recife pertencem a todos os

10 O Projeto Novo Recife consistia, na data de seu lançamento, em 13 torres (sendo duas delas duplas, como se existissem 15 edifícios), entre 36 e 45 andares, divididas em cinco grandes quadras (DIREITOS URBANOS, 2012). seus cidadãos. Vale destacar que o projeto será realizado em um dos bairros mais tradicionais da cidade, numa das paisagens culturais que mais a identificam ${ }^{10}$.

O bairro São José, onde se localiza o cais José Estelita, é um dos mais tradicionais e antigos do Recife. Segundo Pontual (2005), o Recife, até o século XIX, existia sob a influência das águas e dependia do transporte fluvial. Da íntima ligação da cidade com seus corpos hídricos, surgiu o cais José Estelita, no estuário do rio Pina. Este, conforme Barbosa (2014), corresponde a uma das margens líquidas do Recife, com intensa disputa territorial, sendo, antes de tudo, um espaço de importância ecológica, política, histórica e cultural.

No processo de transformação da área do cais José Estelita e do lançamento do Projeto Novo Recife, vemos a conformação de um circuito espacial de inclusão/ exclusão urbana em que se mesclam vários eventos, quais sejam: desativação da Rádio Pina e posterior ativação do Parque dos Manguezais; Projeto Capital; construção da Linha Verde, depois transformada em Via Mangue; elaboração do projeto Complexo Turístico Cultural Recife-Olinda; edificação das Torres Gêmeas pela Moura Dubeux; fundação do Shopping RioMar; efetuação das obras de renovação e requalificação urbana dos armazéns do porto do Recife, associadas ao Projeto Porto Novo. 


\section{O MOVIMENTO OCUPE ESTELITA E A ATUALIDADE DA LUTA DE CLASSES NO ESPAÇO DA CIDADE}

\section{[...] uma história dessa cidade,} aquática, musical, bela e pobre, que muitas vezes foi noiva da revolução, quase se casando. Cerimônia marcada, na undécima hora sempre chegavam sinistros homens, deixando pra trás amargas lembranças vestidas de luto.

(Chico de Oliveira)

Neste artigo, damos enfoque às possiblidades conceituais e teóricas que se atentam para a luta de classes e de fraçóes do capital e seu papel na produção do espaço urbano. Focamos também o importante papel dos movimentos sociais e da utopia na produção da metrópole moderna (LEFEBVRE, 2006, 2008). Lefebvre (2006, p. 98), analisando a produçâo do espaço pela burguesia no capitalismo e as contradições advindas de tal produção, afirma:

A burguesia e o capitalismo têm, desde agora, muita dificuldade para dominar seu produto e seu meio de dominação: o espaço. Eles não podem reduzir a prática (o práticosensível, o corpo, e a prática socioespacial) ao seu espaço abstrato. Contradiçóes novas, as do espaço, surgem e se manifestam.

Em Recife, há um histórico de manifestaçôes ligadas às contradições apontadas por Lefebvre (2006).

Para Oliveira (2008), o Recife foi, no século XX, uma invenção da esquerda. Indo além, ele afirma que, mesmo nos séculos anteriores, essa cidade conformou uma identidade e uma vocação libertária e igualitária. Atualmente, constatamos na sociedade recifense uma batalha em torno da produção do espaço, consubstanciada na luta de empreendedores urbanos e do Estado, ligados por uma coalização de poder, contra grupos e movimentos sociais (Ocupe Estelita, Direitos Urbanos), em projetos como o Novo Recife, exemplo da produçáo do espaço abstrato do capitalismo como fuga das crises do capital via produção de capital fixo (LEFEBVRE, 2006; 2008; HARVEY, 2005; 2011).

Com o apoio de diversos segmentos da sociedade, o Ocupe Estelita surgiu após a apresentação do Projeto Novo Recife. O movimento busca manter vivo o debate sobre o modelo de ocupação verticalizado que a cidade adotou nas últimas décadas. Além de semelhanças com o Occupy Wall Street, como a ausência de programa e a coordenação difusa, o Ocupe Estelita aproxima-se de mobilizaçôes como a do movimento paulistano Baixo Centro, associando açóes culturais e discurso político. Um texto do site do movimento Direitos Urbanos ${ }^{11}$ deixa claro os objetivos do Ocupe Estelita:

[...] questionando a destinação imobiliária, a degradação ambiental, paisagística, histórica e arquitetônica do espaço, acontecem desde 2012 inúmeras manifestaçóes que se denominaram "Ocupe Estelita” (influenciado pelas ocupaçôes dos espaços públicos - praças e ruas, na Europa, em um movimento que reivindicava Democracia Real). Nos "Ocupe
110 Direitos Urbanos corresponde a um grupo formado na internet, em especial na rede de relacionamentos Facebook, com objetivo de articular um diálogo sobre 0 modelo contemporâneo de ocupação e transformação da cidade do Recife. O Direitos Urbanos pode ser compreendido como um grupo de contestação e proposição de ideias, a partir de uma metodologia de atuação variada (ocupações, usos políticos da arte, "batalhas jurídicas", entre outros), organizada a partir de demandas insurgentes e para atuar frente a grandes projetos que requerem uma contestação emergencial. Entre as diversas atuações do grupo, destaca-se o Ocupe Estelita, ocupação festiva e cultural, mas também política e de debate, influenciada por ocupações que sacudiram o mundo a partir de 2011, tais como o Occupy Wall Street, o 15-M e a Primavera Árabe (BARBOSA, 2014). 
Estelita", ante a necessidade de se organizar aquela luta pontual e construir uma pauta política de resistência ao Projeto "Novo Recife", surgiu [agregou-se ao] o grupo "Direitos Urbanos", campo político plural e horizontal em que se deram as discussóes sobre o cais José Estelita, e em que, com o passar do tempo, desembocaram as diversas lutas urbanísticas em defesa da cidade e contra as intervençóes imobiliárias e estatais violadoras dos direitos urbanos e humanos (DIREITOS URBANOS, 2014, n. p.).

Lefebvre (2006) disserta sobre esses tipos de açóes e sobre a luta pelo "direito à diferença” em um período de forte homogeneização advinda das açóes do Estado, através do poder político, do mercado mundial e do mundo da mercadoria - homogeneização implícita na produçáo do espaço abstrato. O autor ratifica a necessidade da restituição de um "código" do espaço:

12 Sobre as possíveis limitações dos movimentos sociais urbanos atuais, David Harvey, em 18 de novembro de 2014, logo após sua visita ao Brasil para o ciclo de conferências "A economia política da urbanização", apontou um paralelo entre o Brasil e a Turquia. Ao analisar a representatividade desses movimentos, ele afirmou: "Mas a 'classe ascendente' também não representa a totalidade da população. $\mathrm{Na}$ Turquia, a massa das classes trabalhadoras islâmicas não se juntou à revolta. Eles já possuíam suas próprias solidariedades culturais (frequentemente anti-modernistas) e relações sociais endurecidas (particularmente no que diz respeito à questão de gênero). Eles não se atraíram pela retórica emancipatória do movimento de protesto, porque aquele movimento não abordou efetivamente sua condição de imensa privação material. Eles gostaram da combinação de shopping centers e mesquitas que o partido dominante, o AKP (Partido da Justiça e Desenvolvimento), estava construindo, e não se importavam com a evidente corrupção em torno da explosão na construção civil, contanto que representasse uma fonte de emprego" (HARVEY, 2015, n.p.).
Restituir um "código" do espaço, ou seja, uma linguagem comum à prática e à teoria, aos habitantes, aos arquitetos, aos científicos \{cientistas\}, pode se considerar taticamente como uma tarefa imediata. Um tal código reapreenderia, inicialmente, a unidade de elementos dissociados: o privado e o público, o encontro e a diferença no espaço. Ele reuniria os termos dispersados pela prática espacial existente e pelas ideologias que a justificam: o micro (a escala ou nível arquitetural) e o macro (atribuído aos urbanistas, aos políticos, aos planificadores), o cotidiano e o urbano, o dentro e o fora $\{$ o interior e o exterior $\}$, o trabalho e o não-trabalho (a festa), o durável e o efêmero etc. O código compor-se-ia, assim, de oposiçóes pertinentes (paradigmáticas), retomadas de termos confundidos na homogeneidade do espaço politicamente controlado (LEFEBVRE, 2006, p. 100).

Quanto à possibilidade de restituição desse "código", é interessante analisar, aqui, o papel dos movimentos sociais urbanos ao longo da história, com seus pontos fortes e suas limitaçôes ${ }^{12}$. Esses movimentos, nas décadas de 1960 e 1970, insuflados pelas teses althussserianas, conquistaram o caráter de vanguarda na luta política das esquerdas - fato que inspirou Manuel Castells a escrever, em 1983, The city and the grassroots.

Para Lefebvre (1991), tais movimentos, a despeito de seu potencial mobilizador, originam-se e organizam-se em torno de reivindicaçóes particulares (ciclovias; espaços públicos, como parques; entre outros), relativas ao consumo no/do ambiente construído. Eles somam diferentes setores sociais que partilhariam uma mesma posição de classe, em termos de consumo do espaço, mas não vão além disso.

Movimentos como o Ocupe Estelita seguem, aparentemente, a lógica lefebvriana de lutas contra a cisão entre valor de uso e de troca do espaço urbano, na qual a sociedade fetichizada é reduzida ao mercado. Para Lefebvre, usar a cidade como valor de uso significa habitá-la nos gestos do cotidiano. A cotidianidade deve ser compreendida, na perspectiva do autor, a partir de três dimensôes dialéticas: trabalho, família e lazer. Tais dimensóes representam questôes tensas, carregadas de conflito, da vida social. Por sua vez, a festa aparece como uma prática revolucionária, como possibilidade de impregnar de não cotidianidade o cotidiano. A festa não desaparece inteiramente do cotidiano: ela está presente nos encontros e nos festejos, no carnaval e nas mobilizaçóes. Isso leva Lefebvre a considerar que a revolução (violenta ou não) adquire um sentido novo, isto é, de ruptura com o cotidiano, de restituição da festa, sendo esse o escopo da revolução possível (virtual) (LEFEBVRE, 1991; 1999). 
Em Recife, há esse tipo de ativismo marcado pela organização de mobilizações de caráter festivo e de uso e fruição do espaço da cidade. Nele, o urbano se apresenta como espaço primeiro de encontros, de ajuntamentos (festa) e de apregoamento de um direito à cidade, que, juntos, podem resgatar o valor de uso ante a lógica das cadeias de equivalência do capitalismo, aquele que transforma tudo, inclusive os espaços da cidade, em valores de troca (FILGUEIRAS, 2014).

Devemos destacar também o caráter moderno e atual dos movimentos sociais em rede, sediados na internet e para além dela, como o caso do grupo Direitos Urbanos no Recife. Castells, em Redes de indignação e esperança: Movimentos sociais na era da internet (2013), entende os movimentos em rede como um padrão emergente nas lutas sociais da atualidade. Sobre a construção dessa nova configuração das lutas e movimentos sociais, ele escreve:

De início, eram uns poucos, aos quais se juntaram centenas, depois formaram-se redes de milhares, depois ganharam o apoio de milhóes, com suas vozes e sua busca interna de esperança, confusas como eram, ultrapassando as ideologias e a publicidade para se conectar com as preocupaçóes reais de pessoas reais na experiência humana real que fora reivindicada. Começou nas redes sociais da internet, já que estas são espaços de autonomia, muito além do controle de governos e empresas, que, ao longo da história, haviam monopolizado os canais de comunicaçáo como alicerces de seu poder. Compartilhando dores e esperanças no livre espaço público da internet, conectando-se entre si e concebendo projetos a partir de múltiplas fontes do ser, indivíduos formaram redes, a despeito de suas opinióes pessoais ou filiaçóes organizacionais. Uniram-se. (CASTELLS, 2013, p. 9-10).

Nossa análise parte do entendimento da lógica de reprodução do capitalismo avançado no mundo moderno e na organização da vida cotidiana, a qual embota o discernimento dos habitantes das metrópoles (SIMMEL, 1976) quanto à diferença entre o espaço urbano usado como valor de uso e valor de troca. Através do conceito de "sociedade burocrática de consumo dirigido", Lefebvre (1991) expóe a racionalidade e o papel do Estado na condução do processo de organização do capitalismo, os aspectos ideológicos dessa condução do consumo, assim como o peso disso no cotidiano da vida nas cidades contemporâneas. Posteriormente, em 1999, ele trata "o urbano" como um possível-impossível, compreendendo a fase crítica (atual) como uma verdadeira caixa-preta, da qual podem sair tanto soluçóes e repostas para as contradiçóes do sistema capitalista e sua correlata produção do espaço, quanto também a ampliação das mesmas contradiçôes. Em A Revolução Urbana, o período das revoluçôes urbanas é compreendido como aquele que pode resgatar o solo urbano das servidóes da propriedade privada e, por conseguinte, da especulação - fato que poderia nos levar a uma verdadeira guerrilha urbana na luta pelo espaço das/nas cidades.

Considerando essas discussões, concluímos, preliminarmente, que movimentos como o Ocupe Estelita não se manifestam como uma estratégia plena de guerrilha urbana do tipo explicitado por Lefebvre. Eles se vinculam mais a uma ideia de utopia que se empenha em transcender o institucional, servindo-se da problemática do real e do possível-impossível. Os movimentos contemporâneos, ademais, conectamse em redes no ciberespaço, ultrapassando o espaço urbano. Nas redes sociais, esses movimentos espalham-se por contágio, produzem um mundo ligado pela internet sem fio, caracterizado pela difusão rápida, viral, de imagens e ideias (CASTELLS, 2013). 
Alexandre Sabino do Nascimento: alexandre.nascimento@upe. br.

Artigo recebido em 15 de setembro de 2015 e aprovado para publicação em 2 de dezembro de 2015.
Finalmente, neste estudo, compartilhamos a tese de Lefebvre de que a revoluçáo urbana e a democracia concreta (desenvolvida) coincidem. Acreditamos que só por essa via a práxis urbana dos grupos e das classes, ou seja, a maneira de eles viverem verdadeiramente a morfologia da qual dispóem, pode confrontar-se com a ideologia urbanística hegemônica. Nesse sentido, a contestação se transforma em reivindicação e, por seu turno, em mudança social.

Com relação à emergência de novos movimentos sociais urbanos baseados em redes no ciberespaço, salientamos a necessidade de estudos mais aprofundados acerca da formação, da dinâmica, do alcance, dos valores e das perspectivas de transformação social de cada um deles.

Todas as características históricas e atuais do Recife aqui apresentadas nos fazem entender essa cidade como um espaço de conflito e de possibilidades de açôes realmente transformadoras do padrão de produção espacial excludente. Elas nos fazem acreditar, ainda, que Recife continua, sim, em seu noivado com a revolução.

\section{REFERÊNCIAS BIBLIOGRÁFICAS}

BARBOSA, D. T. Novos recifes, velhos negócios: política da paisagem no processo contemporâneo de transformaçóes da bacia do Pina - Recife/PE: uma análise do Projeto Novo Recife. 2014. 245 f. Dissertaçáo (Mestrado em Geografia) - Centro de Filosofia e Ciências Humanas, Universidade Federal de Pernambuco, Recife, 2014.

CASTELLS, M. Cidade, democracia e socialismo. Rio de Janeiro: Paz e Terra, 1980.

Redes de indignação e esperança: Movimentos sociais na era da internet. Rio de Janeiro: Zahar, 2013.

BITOUN, J. et al. Regiāo Metropolitana do Recife no Contexto de Pernambuco no Censo 2010. Recife: Observatório das Metrópoles, 2010.

COMPANS, R. Empreendedorismo urbano: entre o discurso e a prática. São Paulo: Unesp, 2005.

CORRÊA, R. L. Inovaçóes espaciais urbanas: algumas reflexóes. Revista Cidades, Presidente Prudente, v. 7, n. 11, p. 149-159, 2010.

DIREITOS URBANOS. Perguntas Frequentes - Projeto Novo Recife. v 1.3. Direitos Urbanos, Recife, dez. 2012. Disponível em: <https://direitosurbanos.wordpress.com/ faqs/faq-projeto-novo-recife/>. Acesso em: 20 ago. 2015.

O que a luta pelo direito à cidade tem a ver com o Ocupe Estelita? Direitos Urbanos, Recife, 27 maio 2014. Disponível em: <https://direitosurbanos.wordpress. com/2014/05/27/o-que-a-luta-pelo-direito-a-cidade-tem-a-ver-com-o-ocupe-estelita/>. Acesso em: 20 ago. 2015.

FILGUEIRAS, M. Produção cultural do Movimento Ocupe Estelita ganha fôlego no Recife e já é chamada de 'novo mangue beat'. O Globo, Rio de Janeiro, 4 dez. 2014. Disponível em: <http://oglobo.globo.com/cultura/producao-cultural-do-movimento-ocupeestelita-ganha-folego-no-recife-ja-chamada-de-novo-mangue-beat-14730838>. Acesso: 5 dez. 2014.

FREITAS, A. Recife tem maior variação no preço do metro quadrado de imóveis, diz Fipe. Diário de Pernambuco, Recife, 5 mar. 2012, n.p. Disponível em: <http://www.old. pernambuco.com/ultimas/nota.asp?materia=20120305171521>. Acesso: 5 ago. 2015.

FUNDAÇÃO JOÃO PINHEIRO. Déficit habitacional municipal no Brasil. Belo Horizonte: Fundação João Pinheiro; Ministério das Cidades, 2013. 78 p.

HARVEY, D. A produção capitalista do espaço. Sáo Paulo: Annablume, 2005 
. O enigma do capital: e as crises do capitalismo. São Paulo: Boitempo, 2011.

Os limites do Capital. São Paulo: Boitempo, 2013.

. A crise da urbanização planetária. Blog da Boitempo. São Paulo, 10 jan. 2015. Disponível em: <http://blogdaboitempo.com.br/2015/01/10/david-harvey-a-crise-da-urbanizacao-planetaria/>. Acesso em: 25 set. 2015.

HOBSBAWM, Eric J. A era do capital: 1848-1875. 3. ed. Rio de Janeiro: Paz e Terra, 1977.

LACERDA, N. Fragmentação e integração: movimentos de reestruturação espacial das metrópoles brasileiras. In: RIBEIRO, A., LIMONAD, E.; GUSMÃO, P. (Org.). Desafios do planejamento. Rio de Janeiro: Letra Capital, 2012. p. 21-42

LEAL, S. M. R. Empresarialismo competitivo e produção imobiliária no processo de organização do espaço metropolitano do Recife. In: COLÓQUIO INTERNACIONAL SOBRE PODER LOCAL, 10., 2006, Salvador. Anais do X Colóquio Internacional sobre Poder Local: Desenvolvimento e Gestão Social do Território. Salvador: NEPOL/UFBA, 2006.

- Papel dos agentes econômicos na governança das metrópoles brasileiras: Inovações e Impactos Territoriais dos Grandes Empreendimentos Imobiliários. In: ENCONTRO NACIONAL DA ANPUR, 14., 2011, Rio de Janeiro. Anais do XIV Encontro Nacional da Anpur. Rio de Janeiro: ANPUR, 2011.

LEFEBVRE, Henri. De lo rural a lo urbano. Barcelona: Ediciones Península, 1969.

. The Production of Space. London: Blackwell, 1991.

A revolução urbana. Belo Horizonte: Ed. UFMG, 1999.

A produção do espaço. Belo Horizonte: [s.n.], 2006. Disponível em: <http://www. mom.arq.ufmg.br/mom/arq_interface/1a_aula/A_producao_do_espaco.pdf $>$. Acesso em: 22 dez. 2015.

Espaço e política. Belo Horizonte: Ed. UFMG, 2008.

LIMONAD, E.; LIMA, I. G. Entre a ordem próxima e a ordem distante: contribuiçóes a partir da obra de Henri Lefebvre. In: LIMONAD, E. (Org.). Entre a Ordem Próxima e a Ordem Distante: contribuiçóes a partir do pensamento de Henri Lefebvre. Niterói: UFF/GECEL, 2003. p. 15-33.

LUCENA, P. Preços dos imóveis em Recife subiram 22,8\% em 5 meses. Acerto de Contas, 24 maio 2012. Disponível em: <http://acertodecontas.blog.br/financiamento-imobiliario/ preos-dos-imveis-em-recife-subiram-228-em-5-meses/>. Acesso em: 1 set. 2015.

MASCARENAS, G.; BIENENSTEIN, G.; SÁNCHEZ, F. O jogo continua: megaeventos esportivos e cidades. Rio de Janeiro: EdUERJ, 2011.

MARICATO. E. O impasse da politica urbana no Brasil. Petrópolis: Vozes, 2011. É a questáo urbana, estúpido! In: et al. Cidades rebeldes. São Paulo: Boitempo; Carta Maior, 2013. p. 19-26

MARX, K. O 18 de Brumário de Luís Bonaparte. São Paulo: Boitempo; Rio de Janeiro: Ed. UFRJ, 2011.

MENDONÇA, A. S. A importância do debate acerca do cais José Estelita e do Projeto Novo Recife para a gestão pública. In: ENCONTRO NACIONAL DA ANPUR, 16., 2015, Belo Horizonte. Anais do XVI Encontro Nacional da Anpur. Belo Horizonte: ANPUR, 2015.

MOLOCHT, H. The City as a Growth Machine: toward a political economy of place. The American Journal of Sociology, v. 82, n. 2, p. 309-332, sep. 1976.

MUITAS realidades dentro das mesmas cidades. Diário de Pernambuco, Recife, 2013. Disponível em: <http://hotsites.diariodepernambuco.com.br/vidaurbana/2013/IBEU/desigualdade.shtml>. Acesso em: 10 set. 2015.

NASCIMENTO, A. S. A difusão de grandes projetos de desenvolvimento urbano como inovaçóes espaciais e seu papel no processo de acumulação e expansão geográfica do 
capital. In: Anais do XIII Simpósio Nacional de Geografia Urbana. Rio de Janeiro, 2013. OBSERVATÓRIO DO RECIFE. Indicadores do Recife. Recife: Observatório do Recife, 2015.

OLIVEIRA, F. Noiva da Revolução; Elegia para uma re(li)gião: Sudene, Nordeste, planejamento e conflito de classes. São Paulo: Boitempo, 2008.

PONTUAL, V. Experiências urbanísticas e representaçóes de cidade: o Recife civilizado. In: CARNEIRO, A. R. S.; PONTUAL, V. (Org.). História e paisagem: ensaios urbanísticos do Recife e São Luís. Recife: Bagaço, 2005. p. 23-48.

PREÇO do metro quadrado no Recife sobe 17,8\% em 2012, maior variação do país. Diário de Pernambuco, Recife, 4 jan. 2013. Disponível em: <http://www.jraluminium.com. br/informativos/06-01-2013-preco-do-metro-quadrado-no-recife-sobe-17-8-em-2012maior-variacao-do-pais/>. Acesso em: 5 ago. 2015.

RECIFE é a 5a cidade com maior concentração de favelas do país. Diário de Pernambuco, Recife, $21 \mathrm{dez}$. 2011. Disponível em: <http://www.old.diariodepernambuco.com.br/ nota.asp?materia=20111221100725>. Acesso em: 10 set. 2015.

REYNALDO, A. et al. A reconfiguração espacial da Região Metropolitana do Recife: processo de fragmentação e integração. Anales del $V$ Seminario Internacional de Investigación en Urbanismo, Barcelona-Buenos Aires, junio 2013. Barcelona: DUOT, 2013, p. $1433-1440$.

ROLNIK, R. Grupos se mobilizam no Recife contra projeto imobiliário no cais José Estelita. Blog da Raquel Rolnik, São Paulo, 19 mar. 2012. Disponível em: <https://raquelrolnik. wordpress.com/2012/03/19/grupos-se-mobilizam-no-recife-contra-projeto-imobiliario-no-cais-jose-estelita/>. Acesso em: 7 set 2015.

. As vozes das ruas: as revoltas de junho e suas interpretaçôes. In: MARICATO, E. et al. Cidades rebeldes. São Paulo: Boitempo; Carta Maior, 2013. p. 7-12.

A Copa do Mundo no Brasil: tsunami de capitais aprofunda a desigualdade urbana. In: JENNINGS, A. et al. Brasil em jogo: o que fica da Copa e das Olimpíadas? São Paulo: Boitempo; Carta Maior, 2014.

SANTOS, M. O Espaço Dividido: os dois circuitos da economia urbana dos países subdesenvolvidos. Rio de Janeiro: Francisco Alves, 1978.

Técnica, espaço, tempo: globalização e meio técnico-científico informacional. São Paulo: Hucitec, 1994.

. Da totalidade ao lugar. São Paulo: Edusp, 2005.

. Espaço e método. 5. ed. São Paulo: Edusp, 2008.

SERVIÇO BRASILEIRO DE APOIO ÀS MICRO E PEQUENAS EMPRESAS - SEBRAE. Cenário econômico das MPEs em Pernambuco. Recife: SEBRAE, 2014.

SIMMEL, G. A Metrópole e a vida mental. In: VELHO, O. G. (Org.). O fenômeno urbano. Rio de Janeiro: Zahar, 1976.

A B S T R A C T : It is observed that to get to the right to the city depends called upon in a truly democratic urban policies structuring and planning that operate mainly in the regulation of the use and occupation of land. These are connected in turn to two processes that are: the expansion of inter-capitalist competition between different fractions of capital-and their effects on different spaces, and the result of the constant reconfiguration of class struggle itself. It points up the protagonist and revolutionary character of the city of Recife in history, connecting it to your social contradictions and its evolution as one of the most unequal cities. The same happens to be the scene of a production space via spatial innovations, via large urban projects, which produce a real space circuit of exclusion, where we highlight the project New Recife. All this makes intensify its character of segregating, 
and also gives rise to the emergence of strategies and tactics for building a social practice through education attempts to urban praxis and public space occupancy acts via cultural activities in region Estelita Pier. This being the construction site of the project New Recife, and the scene of revolutionary experiences about urban issues in Recife.

K E Y W O R D S : rebel cities; spatial circuits of inclusionlexclusion; social movements; metropolis; urban restructuring; Recife; right to the city. 